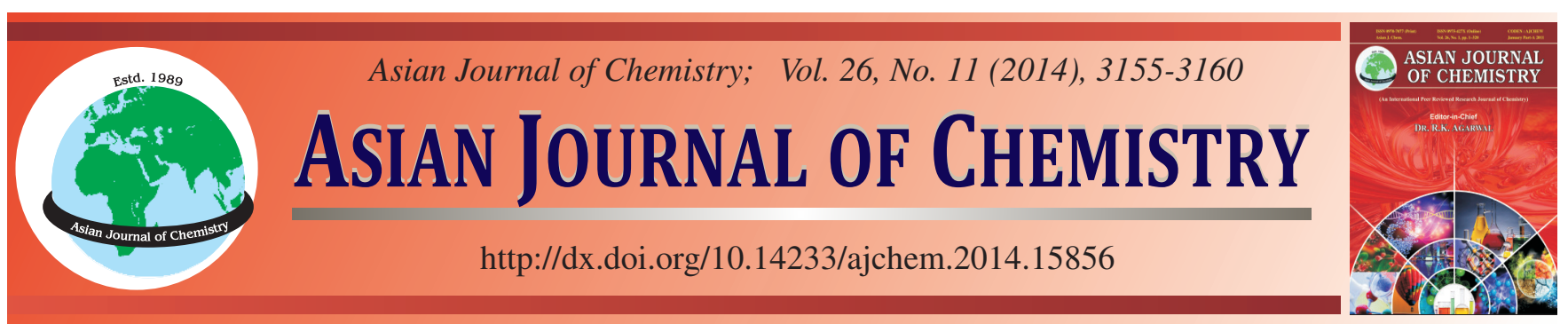

\title{
Degradation Behaviour of Hydrolyzed Polyacrylamide in Solution Induced by Autoxidation of Pyrogallol
}

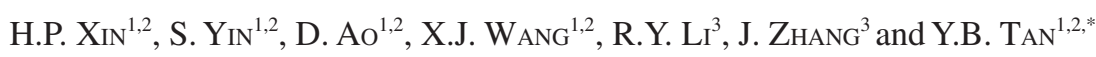

${ }^{1}$ School of Chemistry and Chemical Engineering, Shandong University, Jinan 250100, P.R. China

${ }^{2}$ Key Laboratory of Special Functional Aggregated Materials, Ministry of Education, Shandong University, Jinan 250100, P.R. China

${ }^{3}$ Technology Research Department, CNOOC Research Center, State Key Laboratory of Offshore Oil Exploitation, Beijing 100027, P.R. China

*Corresponding author: Fax: +86 531 88564464; Tel: +86 531 88363502; E-mail: ybtan@ sdu.edu.cn

\begin{abstract}
The degradation of hydrolyzed polyacrylamide in solution was studied using pyrogallol. This degradation could be induced without complicated treatments expect adding pyrogallol to hydrolyzed polyacrylamide solutions. Moreover, hydrolyzed polyacrylamide presented alkaline while progallol autoxidation could be effectively accelerated in alkaline environment. The decrease of apparent viscosity and weight-average molar mass as well as the aggregation radius of hydrolyzed polyacrylamide were evident in the degradation procedure. The mechanism of pyrogallol autoxidation was also investigated by UV-visible spectrum which indicated that superoxide radical generated in the pyrogallol autoxidation could attract the stone bones inducing the degradation of hydrolyzed polyacrylamide.
\end{abstract}

Keywords: Hydrolyzed polyacrylamide, Pyrogallol, Autoxidation, Degradation.

\section{INTRODUCTION}

The hydrolyzed polyacrylamide (HPAM) family is a highly versatile group used in many applications including clarification of drinking water, flocculants for wastewater treatment, oil recovery, soil conditioning, agriculture and biomedical applications ${ }^{1}$. The wide application always accompanied with great amounts of waste water of HPAM. Waste water is difficult to deal with because of its high viscosity. In order to treat this waste water, HPAM should be degradated effectively. With this goal in mind, researchers have done much work ${ }^{2-26}$. Generally, HPAM could be treated by bio-degradation ${ }^{5-7}$, thermal degradation $^{8-10}$, mechanical degradation ${ }^{1-15}$ and chemical degradation ${ }^{16-26}$. Chemical degradation includes photo/photocatalytic degradation and oxidative degradation. Oxidative degradation is an effective method, which is usually induced by redox reagent, Fenton's reagent, peroxide and metallic ions. The free radicals generate from these systems would attack the stone bones of HPAM leading to bond scission.

Pyrogallol could act as oxidative degradation reagent in different $\mathrm{pH}$ solutions. Pyrogallol reacts with oxygen forming semiquinone which is a transient species and finally forming quinine. Superoxide radicals are generated in both of the two stages. Then superoxide radicals attack the stone bones of HPAM and induce the degradation of HPAM. In this paper, the effects of temperature, $\mathrm{pH}$ and salinity on degradation of
HPAM induced was investigated using pyrogallol .The interaction between HPAM and pyrogallol was also studied by apparent viscosity measurements, multiangle laser light scattering, resonance light scattering and UV-visible spectra.

\section{EXPERIMENTAL}

The HPAM (industrial grade, average $\mathrm{M}_{\mathrm{w}}=1.7 \times 10^{7}$, hydrolytic degree $=18 \%$ ) was obtained from French SNF Floergerr Company. Pyrogallol (> $99.9 \%$ ), $\mathrm{KCl}, \mathrm{CaCl}_{2}$, $\mathrm{MgSO}_{4}, \mathrm{NaOH}, \mathrm{HCl}, \mathrm{NaHCO}_{3}, \mathrm{Na}_{2} \mathrm{CO}_{3}$ were obtained from Sinopharm Chemical Reagent Co, Ltd (Shanghai, P.R. China). All reagent, unless special specified, were of analytical grade and were used without further purification. The water was distilled for three times.

Degradation of hydrolyzed polyacrylamide: Hydrolyzed polyacrylamide was dissolved in water and saline solutions with a concentration of $0.12 \mathrm{wt} \%$ then degradated by pyrogallol. The ions concentration of saline solutions was listed in Table-1. Each degradation sample was divided into four equal parts, which were thermal degradated at designed temperature for 0 , 2, 4, 6 and 8 h, respectively. Four sealed high-pressure reactors inside lining polyfluortetraethylene were used during the thermal degradation in order to obtain the desired temperature, which were 50, 65, 80 and $95{ }^{\circ} \mathrm{C}$. Degradation samples were remarked as P-pyrogallol concentration, e. g. P-200 stands for 0.12 wt $\%$ HPAM solution degradated by $200 \mathrm{mg} / \mathrm{L}$ pyrogallol. 
TABLE-1

CONCENTRATION OF IONS IN SALINE SOLUTIONS

\begin{tabular}{cccccccc}
\hline \multirow{2}{*}{ Salinity $(\mathrm{mg} / \mathrm{L})$} & \multicolumn{9}{c}{ Ion Concentration $(\mathrm{mg} / \mathrm{L})$} \\
\cline { 2 - 8 } & $\mathrm{Na}^{+}$and $\mathrm{K}^{+}$ & $\mathrm{Ca}^{+}$ & $\mathrm{Mg}^{2+}$ & $\mathrm{SO}_{4}^{2-}$ & $\mathrm{Cl}^{-}$ & $\mathrm{HCO}_{3}^{-}$ & $\mathrm{CO}_{3}^{2-}$ \\
\hline 2743 & 873 & 47 & 6 & 93 & 833 & 845 & 46 \\
6664 & 2454 & 95 & 38 & 6 & 4039 & 32 & 0 \\
8074 & 2794 & 151 & 82 & 25 & 4415 & 559 & 48 \\
\hline
\end{tabular}

Characterization: The apparent viscosity measurements were carried out on a HAAKE RS75 rheometer (Germany) with coaxial cylinder sensor system (Z41 Ti). The degradations were carried out at $(50 \pm 0.1),(65 \pm 0.1),(80 \pm 0.1)$ and $(95 \pm$ $0.1)^{\circ} \mathrm{C}$, respectively. However, the temperature of the viscosity measurement was maintained at $(25 \pm 0.1){ }^{\circ} \mathrm{C}$. The viscosity measurements were carried out at shear rates of $7.34 \mathrm{~s}^{-1}$.

Multiangle laser light scattering (MALLS) measurements were performed by the Wyatt Technology DAWN HELEOS 18 angle (from $15^{\circ}$ to $165^{\circ}$ ) light scattering detector using a Ga-As laser (658 nm, $40 \mathrm{~mW}$ ). The refractive index increments $(\mathrm{dn} / \mathrm{dc})$ of polyacrylamide in aqueous solution were determined at $25{ }^{\circ} \mathrm{C}$ by an Optilab Rex interferometeric refractometer (Wyatt Technology) at the wavelength of $658 \mathrm{~nm}$ and dynamic light scattering (DLS) was performed on Dawn Heleos, Wyatt QELS and Optilab DSP instrument. The water used for Light Scattering measurements were all filtered through Millipore $0.45 \mu \mathrm{m}$ hydrophilic membranes before using. Solutions were prepared by 1000 times dilution of degradation systems and the concentration of HPAM was diluted from $1200 \mathrm{mg} / \mathrm{L}$ to $1.2 \mathrm{mg} / \mathrm{L}$. Saline solutions with different concentration were prepared for static light scattering measurements by diluting the stock saline solutions.

Resonance light scattering (RLS) measurement was performed at room temperature on a Hitachi F-4500 fluorescence spectrophotometer (Tokyo, Japan). The slit (ex/em) width was $10 \mathrm{~nm} / 2.5 \mathrm{~nm}$. The sensitivities of equipment under detecting conditions were high. The excitation and emission spectra were recorded in range of $300-700 \mathrm{~nm}$ with synchronous at $\lambda_{\mathrm{ex}}=$ $\lambda_{\text {em }}$ (i.e., $\Delta \lambda=0 \mathrm{~nm}$ ) according to the literature ${ }^{27}$.

The UV-visible spectra were measured in range of scanning $300-500 \mathrm{~nm}$ by UV-4100 (Japan) at $25^{\circ} \mathrm{C}$.

\section{RESULTS AND DISCUSSION}

Measurements of apparent viscosity: The effect of pyrogallol concentration on degradation of aqueous solutions of HPAM is shown in Fig. 1. The apparent viscosity of aqueous solutions of HPAM decreased with the increase of degradation time because that the superoxide radicals generated in the pyrogallol autoxidation procedure attacked the HPAM stone bones inducing bond scission. When the pyrogallol concentration was $120 \mathrm{mg} / \mathrm{L}$, the apparent viscosity decreased to 63 $\mathrm{mPas}$ after $8 \mathrm{~h}$ of degradation. At the mean time, the apparent viscosity decreased to $43 \mathrm{mPas}$ when increased the pyrogallol concentration to $200 \mathrm{mg} / \mathrm{L}$, which indicated that the degradation got accelerated. The main reason was that the increase of pyrogallol could generate more superoxide radicals inducing the acceleration of degradation. However, when the pyrogallol concentration was further increased from 200 to $300 \mathrm{mg} / \mathrm{L}$, the degradation was decelerated. After $8 \mathrm{~h}$ of degradation, the apparent viscosity decreased to about $50 \mathrm{mPas}$ no matter the pyrogallol concentration was $240 \mathrm{mg} / \mathrm{L}$ or $300 \mathrm{mg} / \mathrm{L}$. One possible reason was that radicals annihilation occurred as excessive superoxide radicals were generated when more than $200 \mathrm{mg} / \mathrm{L}$ pyrogallol was added inducing that only a part of radicals attacked the HPAM stone bones. In order to obtain the supreme effect of degradation, the optimum concentration of pyrogallol was supposed to be $200 \mathrm{mg} / \mathrm{L}$.

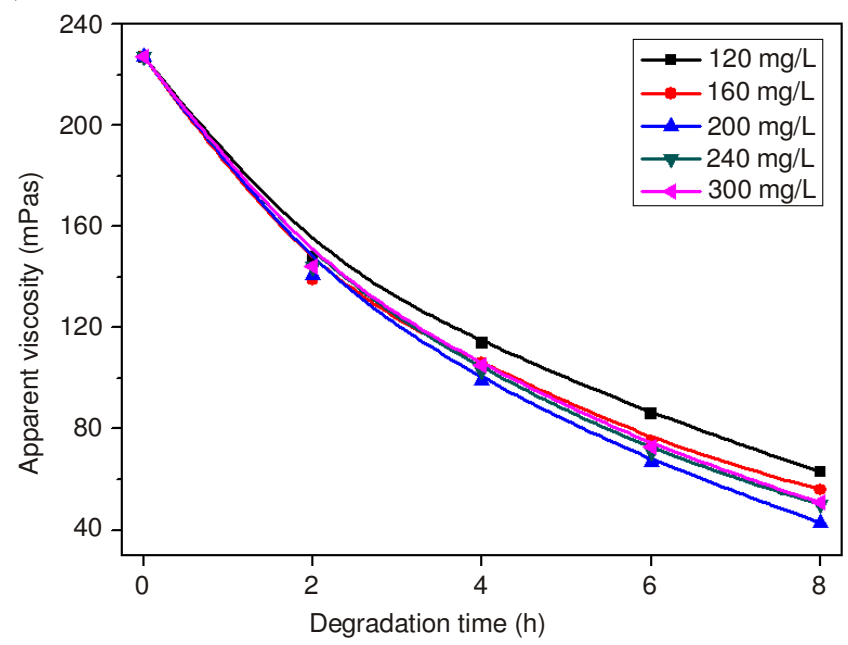

Fig. 1. Apparent viscosity of degradation solutions of HPAM at $\mathrm{pH} 8$ and $65^{\circ} \mathrm{C}$

Fig. 2 shows the effect of degradation temperature on degradation of aqueous solutions of HPAM. As shown in Fig. 2, the apparent viscosity of HPAM solutions decreased while increasing degradation time because that the superoxide radicals generated in the pyrogallol autoxidation procedure attacked the HPAM stone bones inducing bond scission. The decrease of the apparent viscosity of HPAM solutions could be effectively accelerated with increasing temperature. The apparent viscosity of aqueous solutions of HPAM decreased to 127 and $43 \mathrm{mPas}$ after $8 \mathrm{~h}$ of degradation at $50{ }^{\circ} \mathrm{C}$ and $65^{\circ} \mathrm{C}$, respectively. When temperature was risen to $80{ }^{\circ} \mathrm{C}$ and $95^{\circ} \mathrm{C}$, the apparent viscosity decreased to less than 46 and 4 $\mathrm{mPas}$ in $2 \mathrm{~h}$, respectively. The results indicated that the increase of temperature could effectively accelerate the degradation of aqueous solutions of HPAM. The reason was supposed to be that the increase of temperature could improve the reaction rate of the pyrogallol autoxidation and finally accelerate the degradation. The increase of temperature could also give rise to crimple of HPAM molecules due to its dehydrating and destruction of the associational structure, which also contribute to the decrease of the apparent viscosity ${ }^{28}$.

Fig. 3 shows the effect of $\mathrm{pH}$ on degradation of aqueous solutions of HPAM. The $\mathrm{pH}$ of samples was adjusted from 4 to 9 using $\mathrm{NaOH}(0.1 \mathrm{~mol} / \mathrm{L})$ and $\mathrm{HCl}(0.1 \mathrm{~mol} / \mathrm{L})$. The 
apparent viscosity of aqueous solutions of HPAM decreased in both acid solution and alkaline solution. The apparent viscosity decreased to $100 \mathrm{mPas}$ in $8 \mathrm{~h}$ at $\mathrm{pH} 4$ and it decreased to $38 \mathrm{mPas}$ at $\mathrm{pH} 9$ as shown in Fig. 3. The increase of $\mathrm{pH}$ would lead to the acceleration of degradation, because there would be more $\mathrm{OH}^{-}$in higher alkalinity which participated in the autoxidation of pyrogallol. The reason was supposed that $\mathrm{H}^{+}$of phenolic hydroxyl group could also disassociated easily in high alkalinity and negatively charged groups in the unstable high energy state were formed which could be oxidized easily.

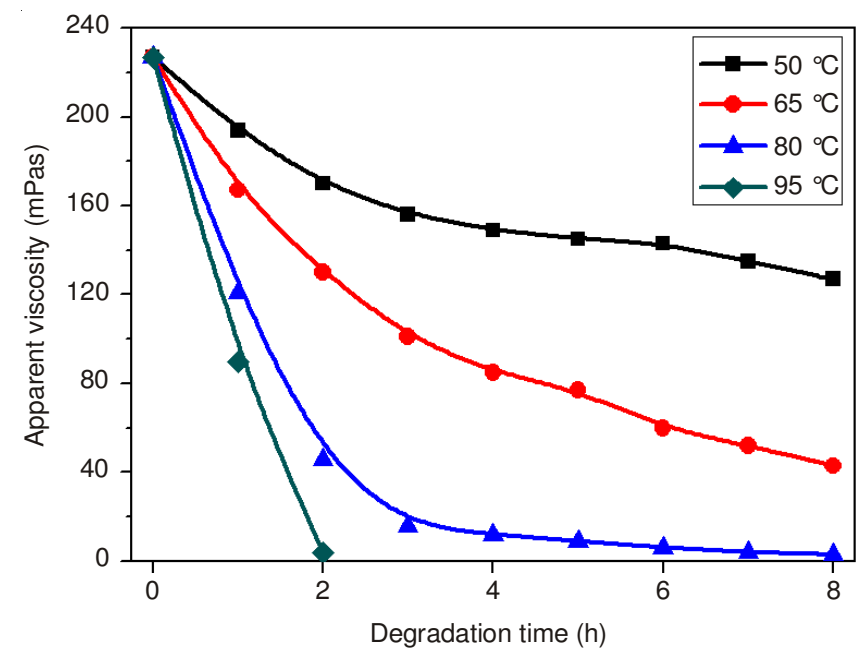

Fig. 2. Apparent viscosity of P-200 solutions degradated by pyrogallol at $\mathrm{pH} 8$ and different temperature

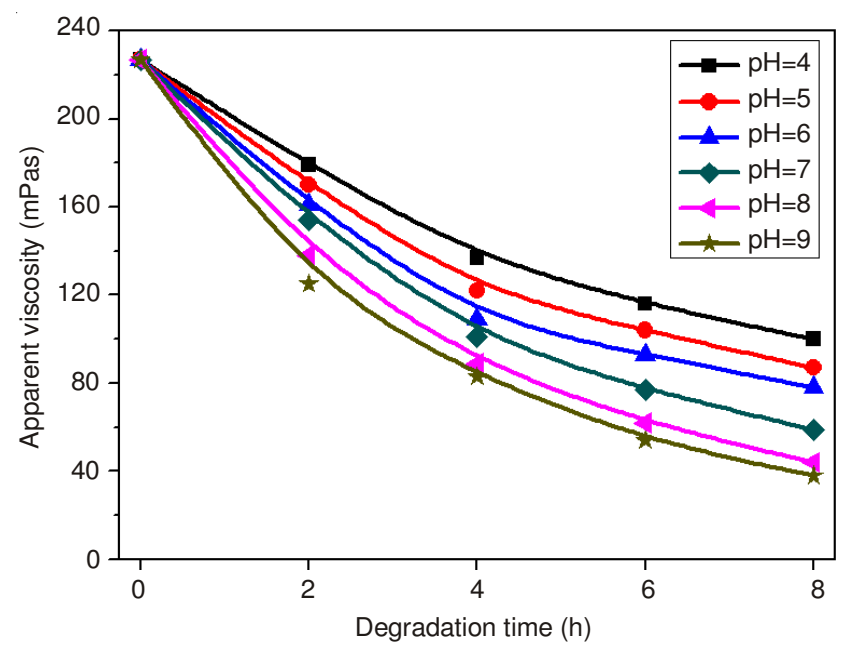

Fig. 3. Apparent viscosity of P-200 solutions degradated at different $\mathrm{pH}$ and $65{ }^{\circ} \mathrm{C}$

Salinity could also effect on degradation of HPAM saline solutions. The apparent viscosity of HPAM in saline solutions decreased with the increase of salinity as shown in Fig. 4. When the salinity was $2743 \mathrm{mg} / \mathrm{L}$, the viscosity of HPAM saline solution decreased from $44 \mathrm{mPas}$ to $5.2 \mathrm{mPas}$. Increasing salinity to 6664 and $8074 \mathrm{mg} / \mathrm{L}$, the viscosity decreased from 16.7 and $12.9 \mathrm{mPas}$ to 4.6 and $4.3 \mathrm{mPas}$, respectively. The decreasing amplitude of viscosity decreased with the increase of salinity. However, the apparent viscosity of HPAM saline solution with lower salinity was higher than those with higher salinity during the degradation procedure. Contrasted with the degradation in aqueous solutions, the final apparent viscosity of HPAM saline solutions were less than $6 \mathrm{mPas}$ closing to water which is $1 \mathrm{mPas}$ after $8 \mathrm{~h}$ of degradation. The main reason may be that the existence of salt ions would compress the electric double layer of HPAM chains which would lead to the decrease of hydrodynamic radius finally inducing the decrease of apparent viscosity. The higher the salinity was, the more intensively the electric double layer was compressed. Thus the increase of salinity would induce the decrease of viscosity.

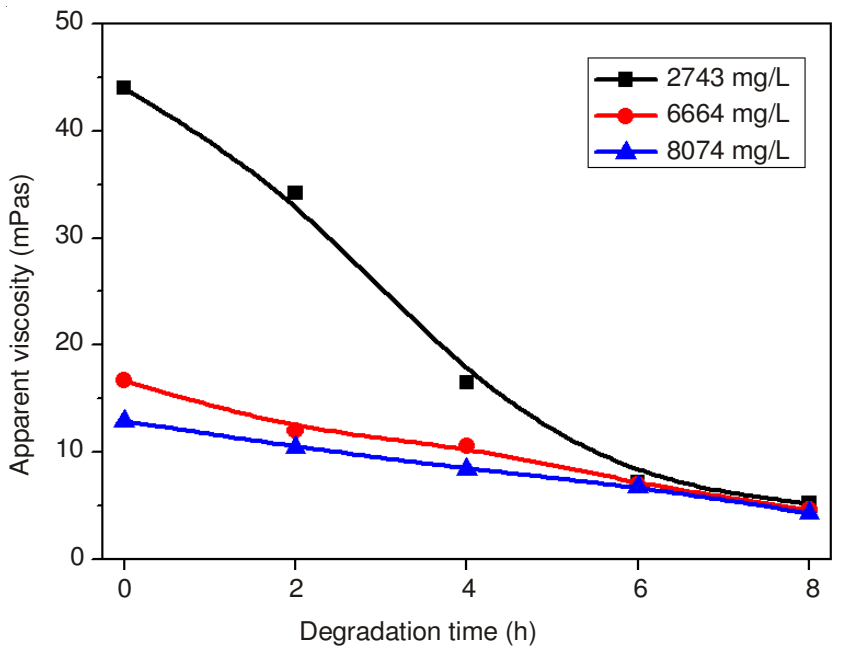

Fig. 4. Apparent viscosity of P-200 saline solutions at $\mathrm{pH} 8$ and $65{ }^{\circ} \mathrm{C}$ with different salinity

Static light scattering measurements: In static light scattering (SLS), we are able to obtain the weight-average molar mass $\left(\mathrm{M}_{\mathrm{w}}\right)$, the second-order virial coefficient $\mathrm{A}_{2}$ and the mean square radius $\left\langle r_{g}^{2}\right\rangle$ of polymer chains from the angular dependence of the excess absolute scattering intensity, known as the Rayleigh ratio $\mathrm{R}(\theta)$, on the basis of

$$
\frac{\mathrm{K}^{*} \mathrm{C}}{\mathrm{R}(\theta)}=\frac{1}{\mathrm{M}_{\mathrm{w}}}\left(1+\frac{1}{3}<\mathrm{r}_{\mathrm{g}}^{2}>\mathrm{q}^{2}\right)+2 \mathrm{~A}_{2} \mathrm{c}
$$

where $K^{*}=4 \pi(d n / d c)^{2} n_{0} /\left(N_{A} \lambda_{0}{ }^{4}\right)$ and, $q=\left(4 \pi n_{0} / \lambda_{0}\right) \sin (\theta / 2)$, with $\mathrm{n}_{\mathrm{o}}, \mathrm{dn} / \mathrm{dc}, \lambda_{0}$ and $\theta$ being the solvent refractive index, the specific refractive index increment, the wavelength of the incident light in vacuum and the scattering angle, respectively ${ }^{29}$

Fig. 5 shows the static Zimm plot of $0.12 \mathrm{wt} \%$ aqueous solution of HPAM degradated by $200 \mathrm{mg} / \mathrm{L}$ pyrogallol at $\mathrm{pH}$ 8 and $65{ }^{\circ} \mathrm{C}$ after 8 h. Static light scattering measurements were carried in $\mathrm{NaCl}(1 \mathrm{~mol} / \mathrm{L})$ solutions, where $\mathrm{C}$ ranges from $1.0 \times 10^{-6}$ to $9.0 \times 10^{-6} \mathrm{~g} / \mathrm{mL}$. In the measurements, the value of $\mathrm{dn} / \mathrm{dc}$ was $0.1556 \mathrm{~mL} / \mathrm{g}$. The variation of weight-average molar mass $\mathrm{M}_{\mathrm{w}}$ of HPAM at different degradation time was shown in Fig. 6. Degradated by pyrogallol at $65^{\circ} \mathrm{C}$, the $\mathrm{M}_{\mathrm{w}}$ of HPAM decreased from $1.7 \times 10^{7} \mathrm{~g} / \mathrm{mol}$ to $1.9 \times 10^{6} \mathrm{~g} / \mathrm{mol}$ after $8 \mathrm{~h}$. The data of SLS measurements indicated that the $\mathrm{M}_{\mathrm{w}}$ of HPAM decreased with the increase of degradation time. The decrease of $\mathrm{Mw}$ would induce the decrease of hydrodynamic radius as well as viscosity. 


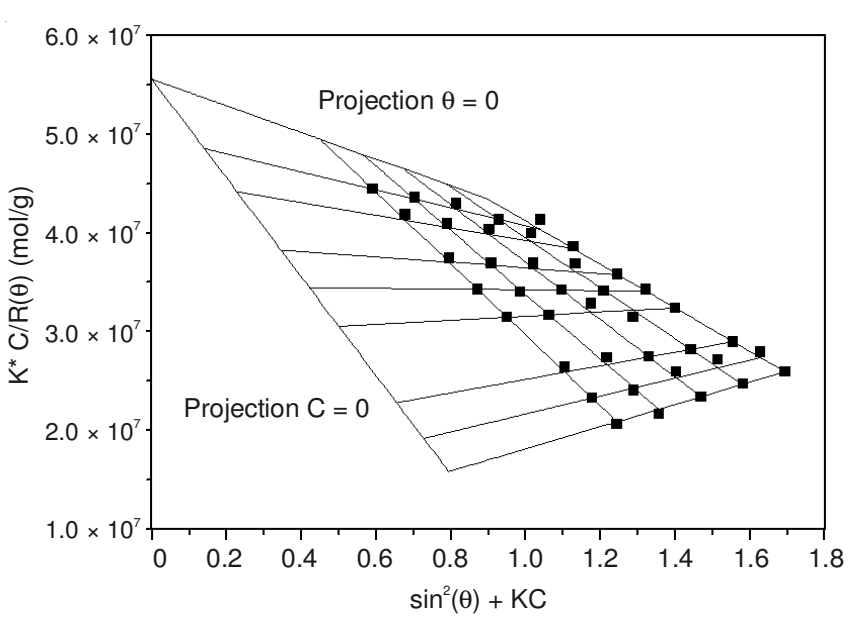

Fig. 5. Typical Zimm plot for HPAM in $\mathrm{NaCl}$ aqueous

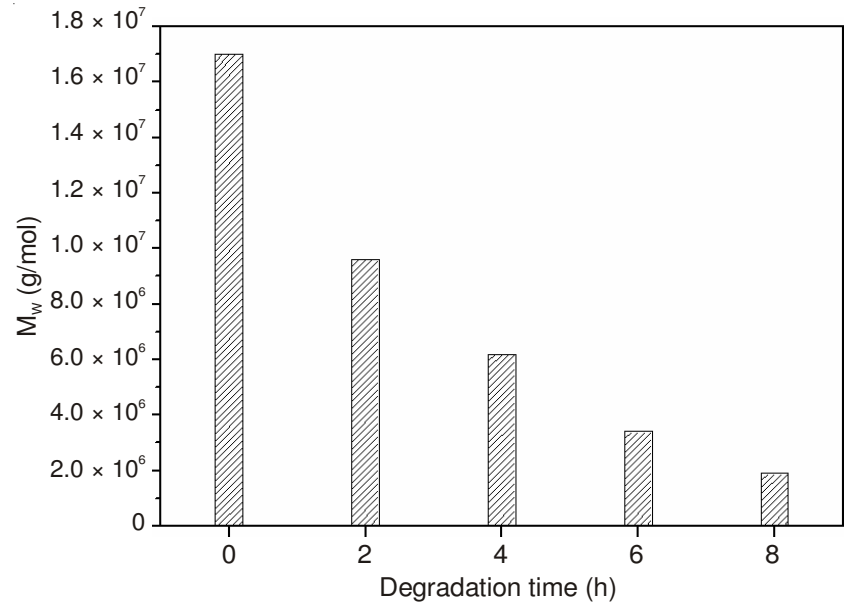

Fig. 6. $\mathrm{M}_{\mathrm{w}}$ of $\mathrm{P}-200$ solution at $\mathrm{pH} 8$ and $65^{\circ} \mathrm{C}$

Dynamic light scattering measurements: The average hydrodynamic radius $\left(\mathrm{R}_{\mathrm{h}}\right)$ of HPAM, obtained from dynamic light scattering (DLS), is an important physical parameter, because a lot of information about the size of molecules and the state of interaction between molecules could be obtained from the DLS analysis. The distribution of the hydrodynamic radius and the average hydrodynamic radius of HPAM at different degradation time in aqueous solution was obtained by DLS as shown in Fig. 7(a) and 7(b). The distribution of hydrodynamic radius of HPAM in water shift to smaller size with the increase of degradation time as shown in Fig. 7(a) and the average hydrodynamic radius of the HPAM also decreased with the increase of degradation time as shown in Fig. 7(b). During the degradation procedure, the decrease of average hydrodynamic radius might attribute to the rupture of backbones. These results indicated that chain-breaking process happened as the superoxide radicals attacked the stone bones of HPAM.

Resonance light scattering measurements: The information of the aggregation of HPAM in the presence of pyrogallol could be studied by RLS, because RLS is extremely sensitive and selective in probing the aggregation of the molecular chains. Fig. 8 shows the RLS spectra of the HPAM aggregation of different degradation time. Their maximum scattering wavelengths were around $472 \mathrm{~nm}$ and two smaller scattering peaking at 529 and $543 \mathrm{~nm}$. The three peaks are the RLS information of the aggregation of the HPAM samples. Considering the sensitivity of detection, the maximum scatting wavelength was selected for further work. The RLS intensity decreased with the increase of degradation time, which indicated that HPAM could effectively be degradated to smaller size by pyrogallol. These results were consistent with the results from dynamic light scattering measurements.

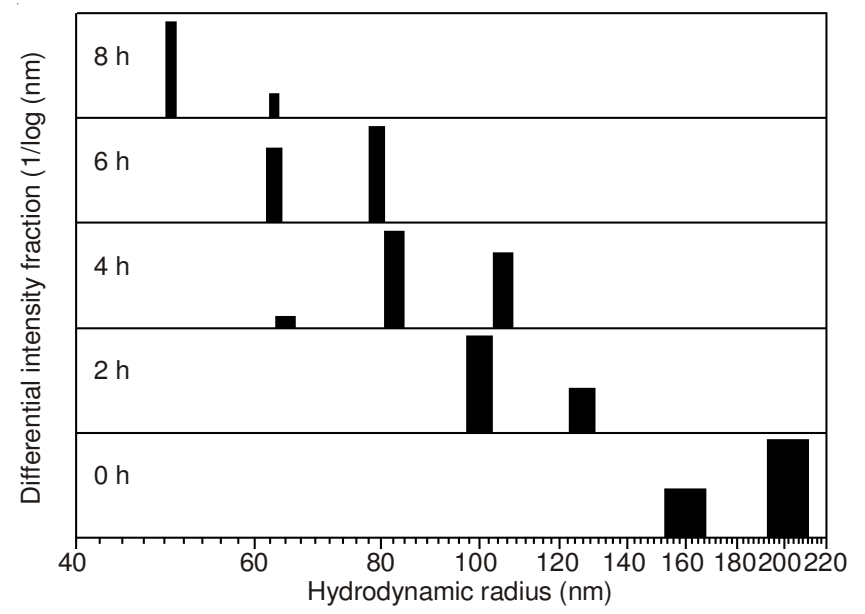

(a)

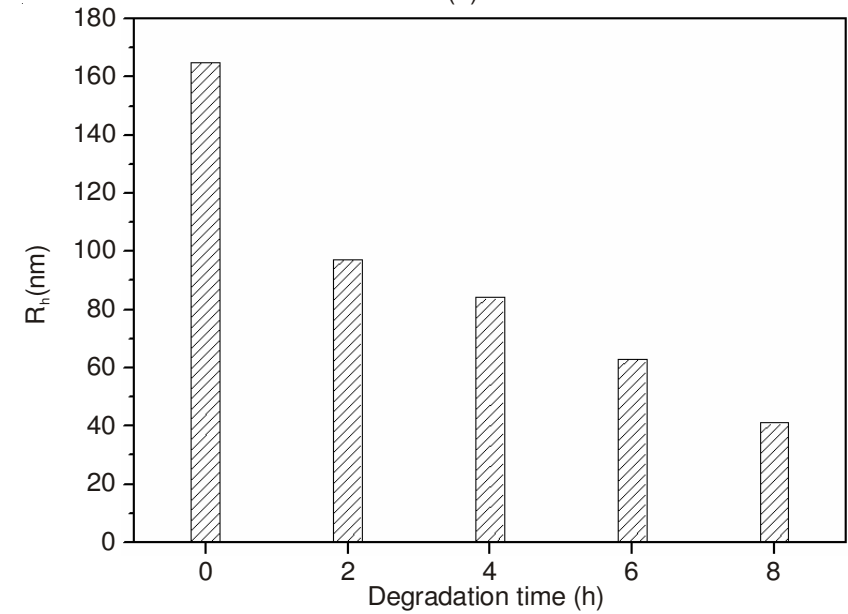

(b)

Fig. 7. The distribution of the hydrodynamic radius (a) and average hydrodynamic radius (b) of $\mathrm{P}-200$ at $\mathrm{pH} 8$ and $65{ }^{\circ} \mathrm{C}$

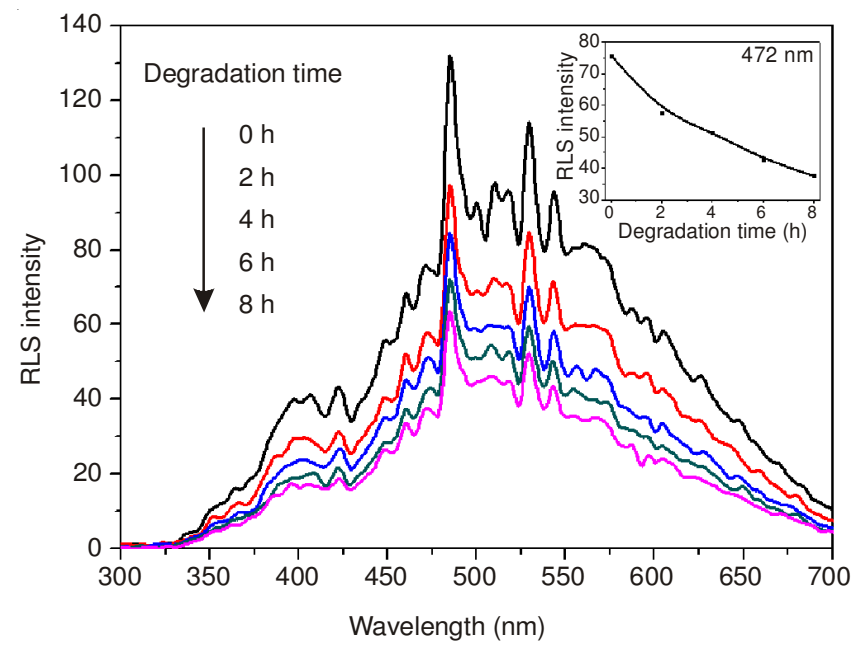

Fig. 8. The RLS spectra of the aggregation of P-200 solutions at $\mathrm{pH} 8$ and $65{ }^{\circ} \mathrm{C}$ 
UV-visible measurements: Fig. 9 shows the UV-visible spectra of pyrogallol autoxidation in water. According to literatures, pyrogallol autoxidation is a very rapid process ${ }^{30}$. The pattern of pyrogallol autoxidation exhibit strong absorption bands centered around $320 \mathrm{~nm}$ and $420 \mathrm{~nm}$. The strong absorption band centered around $320 \mathrm{~nm}$ is a characteristic absorption peak of a semiquinone which is a transeient species from pyrogallol to its final autoxidation product. The strong absorption bands centered around $420 \mathrm{~nm}$ is the characteristic absorption peak of the quinine which is the final autoxidation product. The data of the experiment indicated that the intensities of the bands around $320 \mathrm{~nm}$ and $420 \mathrm{~nm}$ increased at the beginning which indicated that both of the semiquinone and quinine formed at the beginning. Then the band around 320 $\mathrm{nm}$ increased to a maximum value and remained unchanged while the band around $420 \mathrm{~nm}$ increased all along. The possible reason was that the semiquinone formed was further autoxidated to quinine instantly inducing that the semiquinone concentration kept invariableness while the quinine concentration increased.

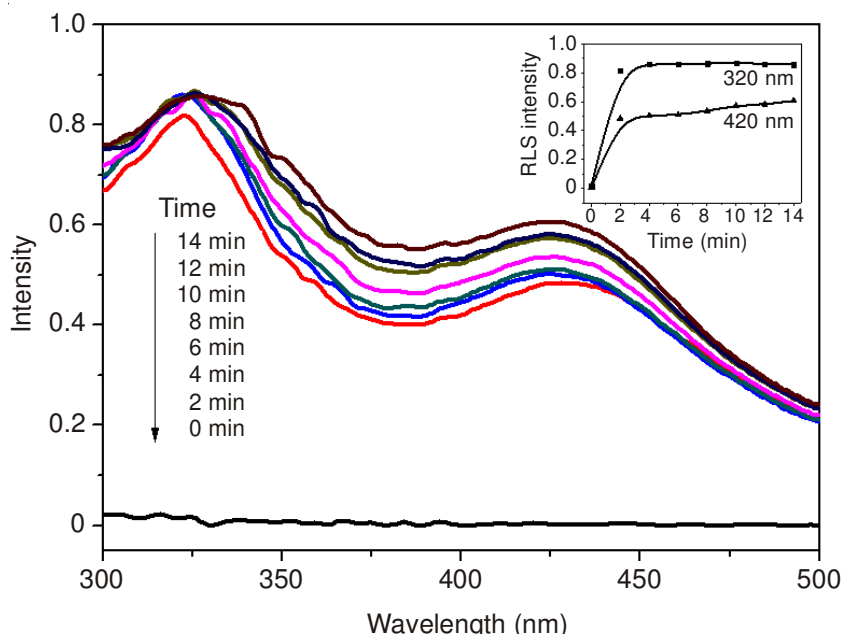

Fig. 9. UV-visible spectra of $200 \mathrm{mg} / \mathrm{L}$ pyrogallol autoxidation in water at $\mathrm{pH} 8$ and $65^{\circ} \mathrm{C}$

Fig. 10 shows the UV-visible spectra of pyrogallol autoxidation in aqueous solution of HPAM. Autoxidated in HPAM aqueous solution, the band around $420 \mathrm{~nm}$ didn't appear which indicated that the autoxidation in HPAM solution was not as rapid as in water. The main reason may be that the autoxidation was decelerated due to the high viscosity of HPAM solution which restrained the contact between pyrogallol and oxygen. Thus, only the semiquinine forms due to the lack of oxygen in the initial $8 \mathrm{~h}$ of the degradation.

The mechanism of pyrogallol autoxidation in water is complicated because that pyrogallol dipolymer formed via polycondensation in the autoxidation process ${ }^{30}$. However, it could be simplified as shown in Fig. 11(a) which could also illustrate the mechanism validity. Due to the lack of oxygen, pyrogallol autoxidation in aqueous solution of HPAM become relatively uncomplicated. Based on the data of UV-visible spectra, only the semiquinone formed in the autoxidation procedure in HPAM solutions. The mechanism of pyrogallol autoxidation in aqueous solution of HPAM was supposed as shown in Fig. 11(b).

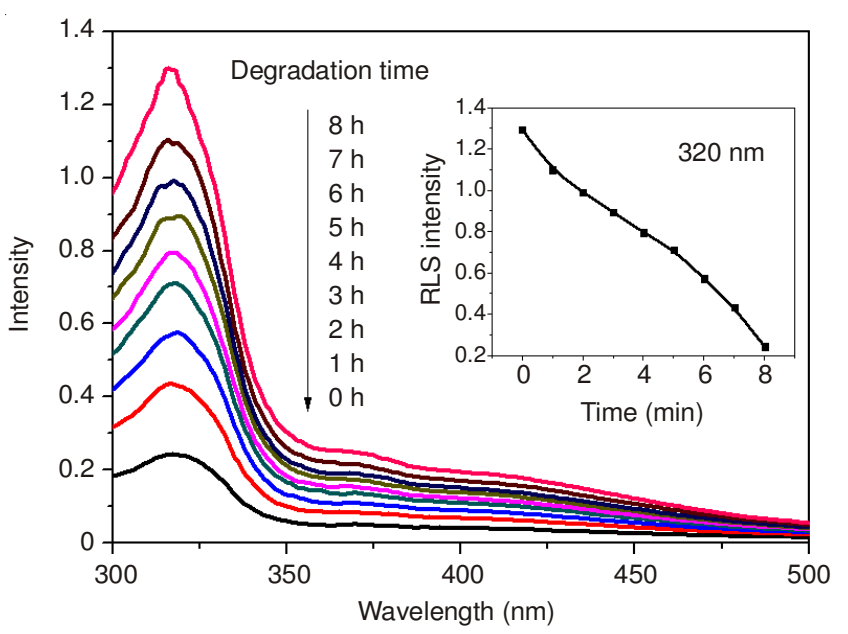

Fig. 10. UV-visible spectra of P-200 at $\mathrm{pH} 8$ and $65^{\circ} \mathrm{C}$

The mechanism of autoxidation was supposed as follows: Generation of free radicals:

$$
\begin{aligned}
& 1+\mathrm{OH}^{-} \rightarrow 2+\mathrm{H}_{2} \mathrm{O} \\
& 2+\mathrm{O}_{2}+\mathrm{OH}^{-} \rightarrow 3+\mathrm{O}_{2}^{\cdot-}+\mathrm{H}_{2} \mathrm{O} \\
& 2+\mathrm{O}_{2}^{--}+\mathrm{H}_{2} \mathrm{O} \rightarrow 3+\mathrm{H}_{2} \mathrm{O}_{2}+\mathrm{OH}^{-} \\
& \mathrm{O}_{2}^{\cdot-}+\mathrm{H}_{2} \mathrm{O}_{2} \rightarrow \mathrm{O}_{2}+\mathrm{OH}^{-}+\mathrm{OH}^{\bullet} \\
& \mathrm{OH}^{\bullet}+\mathrm{PH} \rightarrow \mathrm{P}^{\bullet}+\mathrm{H}_{2} \mathrm{O}
\end{aligned}
$$

Transferring of free radicals:

$$
\begin{aligned}
& \mathrm{P}^{\bullet}+\mathrm{O}_{2} \rightarrow \mathrm{POO}^{\bullet} \\
& \mathrm{POO} \rightarrow \mathrm{POOH}+\mathrm{P}^{\bullet} \\
& \mathrm{POOH} \rightarrow \mathrm{PO}^{\bullet}+\mathrm{OH}^{\bullet} \\
& \mathrm{PH}+\mathrm{OH}^{\bullet} \rightarrow \mathrm{PO}^{\bullet}+\mathrm{H}_{2} \mathrm{O} \\
& \mathrm{O}_{2}^{\bullet-}+\mathrm{PH} \rightarrow \mathrm{PO}^{\bullet}+\mathrm{OH}^{-}
\end{aligned}
$$

Chain breaking induced by radicals:

$$
\mathrm{POO}^{\bullet} \rightarrow \mathrm{P}_{1}+\mathrm{P}_{2}
$$

\section{Conclusion}

In this paper, we investigated the effect of pyrogallol autoxidation on the degradation of HPAM in aqueous and saline solutions. Degradated by $200 \mathrm{mg} / \mathrm{L}$ of pyrogallol, the apparent viscosity of $0.12 \mathrm{wt} \%$ HPAM solution decreased from 227 mPas to $43 \mathrm{mPas}$ while the $\mathrm{M}_{\mathrm{w}}$ decreased from $1.7 \times 10^{7} \mathrm{~g} / \mathrm{mol}$ to $1.9 \times 10^{6} \mathrm{~g} / \mathrm{mol}$ in $8 \mathrm{~h}$ at $65^{\circ} \mathrm{C}$. The apparent viscosity measurements also showed that HPAM degradation could be accelerated with increasing temperature and alkalinity. Multiangle laser light scattering showed that the average hydrodynamic radius and weight-average molar mass of HPAM decreased during the degradation procedure. Resonance light scattering measurement showed that HPAM could be effectively degradated to smaller size by pyrogallol. Pyrogallol autoxidation provide a way of HPAM degradation in different $\mathrm{pH}$ solutions. The increase of degradation rate will be investigated in the further research.

\section{ACKNOWLEDGEMENTS}

The authors gratefully acknowledged the financial support from Major Research of the Ministry of Science and Technology, China (Grant No. 2011ZX05024-004-08). 
<smiles>Oc1cccc(O)c1O</smiles>

1<smiles>O=C(O)CC(=O)O</smiles>

2<smiles>O=C([O-])CC(=O)O</smiles>

3<smiles>O=C1C=CC=C([O-])C1=O</smiles>

4

$\mathbf{a}$<smiles>O=C(O)CC(O)COc1c(O)cccc1O</smiles>

Fig. 11. Autoxidation of pyrogallol in water (a) and HPAM aqueous solutions (b)

\section{REFERENCES}

1. M.J. Caulfield, G.G. Qiao and D.H. Solomon, Chem. Rev., 102, 3067 (2002).

2. M.J. Caulfield, X.J. Hao, G.G. Qiao and D.H. Solomon, Polymer, 44, 1331 (2003).

3. M.J. Caulfield, X.J. Hao, G.G. Qiao and D.H. Solomon, Polymer, 44, 3817 (2003).

4. D. Neradovic, M.J. Steenbergen, L. Vansteelant, Y.J. Meijer, C.F. Nostrum and W.E. Hennink, Macromol., 36, 7491 (2003).

5. Q.X. Wen, Z.Q. Chen, Y. Zhao, H.C. Zhang and Y.J. Feng, J. Hazard. Mater., 175, 955 (2010).

6. K. Nakamiya and S. Kinoshita, J. Fermen. Bioeng., 80, 418 (1995).

7. W.D. Chen and H. Y. Liu, Biodegradation of Hydrolyzed Polyacrylamides in Aqueous Solution. Modern Multidisciplinary Applied Microbiology: Exploiting Microbes and Their Interactions, Weinheim: Wiley, pp. 194-199 (2008).

8. W.M. Leung, D.E. Axelson and J.D. Van Dyke, J. Polym. Sci. A; Polym. Chem., 25, 1825 (1987).

9. M.-H. Yang, Polym. Test., 17, 191 (1998).

10. G. Muller, J.C. Fenyo and E. Selegny, J. Appl. Polym. Sci., 25, 627 (1980).

11. A.H. Abdel-Alim and A.E. Hamielec, J. Appl. Polym. Sci., 17, 3769 (1973).

12. W. Nagashiro and T. Tsunoda, J. Appl. Polym. Sci., 21, 1149 (1977).

13. A.M. Basedow, K.H. Ebert and H. Hunger, Makromol. Chem., 180, 411 (1979).
14. S.P. Vijayalakshmi and G. Madras, Polym. Degrad. Stab., 84, 341 (2004).

15. H.Y. Yen and M.H. Yang, Polym. Test., 22, 129 (2003).

16. S.P. Vijayalakshmi, D. Senapati and G. Madras, Polym. Degrad. Stab., 87, 521 (2005).

17. S.P. Vijayalakshmi and G. Madras, J. Appl. Polym. Sci., 100, 3997 (2006).

18. J.H. Li, X. Yang, X.D. Yu, L.L. Xu, W.L. Kang, W.H. Yan, H.F. Gao, Z.H. Liu and Y.H. Guo, Appl. Surf. Sci., 255, 3731(2009).

19. J. Suzuki, S. Iizuka and S. Suzuki, J. Appl. Polym. Sci., 22, 2109 (1978).

20. S.P. Vijayalakshmi, A. Raichur and G. Madras, J. Appl. Polym. Sci., 101, 3067 (2006)

21. D.K. Ramsden, S. Fielding, N. Atkinson and M. Boota, Polym. Degrad. Stab., 17, 49 (1987).

22. J.P. Gao, J.G. Yu, W. Wang and T. Lin, J. Appl. Polym. Sci., 69, 791 (1998).

23. U. Gröllmann and W. Schnabel, Polym. Degrad. Stab., 4, 203(1982).

24. D.K. Ramsden and K. McKay, Polym. Degrad. Stab., 14, 217 (1986).

25. T. Liu, H. You and Q.W. Chen, J. Hazard. Mater., 162, 860 (2009).

26. D.K. Ramsden and K. McKay, Polym. Degrad. Stab., 15, 15 (1986).

27. Y.B. Li, X.D. Chen, M.Q. Zhang, W.A. Luo, J. Yang and F.M. Zhu, Macromolecules., 41, 4873 (2008).

28. X. Xin, G.Y. Xu, D. Wu, Y.M. Li and X.R. Cao, Colloids Surf. A, 305, 138 (2007).

29. B.H. Zimm, J. Chem. Phys., 16, 1099 (1948).

30. R.M. Gao, Z.B. Yuan, Z.Q. Zhao and X.R. Gao, Bioelectrochem. Bioenerg., 45, 41 (1998). 